\title{
A standardized approach to access in patients requiring complex endovascular aortic therapy
}

\author{
Matthew J. Sideman', Dawn S. Hui ${ }^{2}$ \\ ${ }^{1}$ Division of Vascular Surgery, Department of Surgery, Joe R. and Teresa Long Lozano School of Medicine, University of Texas Health San Antonio, \\ San Antonio, TX, USA; ${ }^{2}$ Department of Cardiothoracic Surgery, Joe R. and Teresa Long Lozano School of Medicine, University of Texas Health \\ San Antonio, San Antonio, TX, USA \\ Correspondence to: Dawn S. Hui, MD. Department of Cardiothoracic Surgery, UT Health San Antonio, 7703 Floyd Curl Drive, Suite 211L, San \\ Antonio, TX 78229, USA. Email: huid@uthscsa.edu.
}

Submitted May 17, 2021. Accepted for publication Oct 13, 2021.

doi: 10.21037/acs-2021-taes-19

View this article at: https://dx.doi.org/10.21037/acs-2021-taes-19

\section{Introduction}

The increasing complexity of endovascular therapy for aortic pathology in the past few decades has been facilitated by improvements in access techniques and delivery systems. Successful vascular access management is a critical element to the safe and effective conduct of these procedures. In this editorial, we outline the principles of a standardized approach to vascular access. The basic approach involves: (I) preoperative planning, which incorporates clinical, imaging, and procedural considerations; (II) preoperative plan for potential or anticipated access-site complications; (III) intraoperative confirmation and reassessment; (IV) clear communication and team readiness for closure complications.

Treatment of aortic pathology is increasingly being performed by endovascular techniques. Given the size of devices necessary to deliver an aortic endograft, transfemoral access has been the standard approach, with iliac access as the secondary approach. The main access considerations are accommodating large caliber devices, avoiding complications, and safely closing the access site(s). Access-related complications may range from local site bleeding to dissection to arterial rupture. Cutdown for failure of percutaneous access is associated with a number of adverse events (1). As delivery and access closure devices (ACDs) have evolved, the feasibility of safe total percutaneous access has increased. This requires a consistent method for pre-operative, intra-operative, and post-operative vascular access management.
Encouragingly, percutaneous-only access is increasing while access-related complications are decreasing. A meta-analysis of eleven studies on thoracic endovascular aortic repair (TEVAR) for descending thoracic aortic aneurysms found a pooled rate of $9.7 \%$ for vascular complications requiring repair, without reporting on an open versus percutaneous approach (2). In the Gore Global Registry for Endovascular Aortic Treatment (GREAT) (3), percutaneous-only access for thoracic endovascular aortic repair (TEVAR) was 33.4\% (slightly less than for EVAR at 44.4\%); access site complication rates for TEVAR were $1.9 \%$. More recent observational studies have demonstrated higher rates of totally percutaneous access at $45.7-87.1 \%$ with only slightly higher rates of access-related complications $(2.4-4.3 \%)(4,5)$. Gender plays a significant role, with women having a threefold rate of conduit need and a significantly higher rate of accessrelated complications regardless of whether the technique is percutaneous or open (6).

A standardized approach begins with pre-operative evaluation of the vasculature to determine the appropriate access site and technique, anticipate potential complications, and plan for bailout techniques should they become necessary. Both clinical and imaging-based [typically helical computed tomography (CT)] aspects are important, including factors related to the vessel itself (diameter, anatomy, calcification or atherosclerotic severity, tortuosity, distal disease), and the patient (obesity, prior femoral interventions and closure devices, underlying aortic pathology). At the start of the procedure, the safety 
and efficacy of the initial access plan is confirmed with additional imaging modalities such as ultrasound and angiography. These modalities may serve as the primary evaluation in urgent or emergent cases, where pre-operative $\mathrm{CT}$ assessment may not be adequate. Of utmost importance is the surgeons' ability to be flexible and integrate new information, particularly when it suggests that an alternative approach is significantly safer.

Once the approach is determined, arterial entry technique must be meticulous and with a plan for arterial closure in mind. For percutaneous access, a combination of palpation, knowledge of anatomy, and confirmatory imaging is used to determine the ideal puncture site. The preclose technique is used at this time; any signs of persistent difficulty performing this step should prompt re-evaluation of the access plan. In a single-institution series, obesity per se was not a predictor of ACD failure; rather, access vessel diameter-to-sheath ratio and adjunctive iliac stents predicted failure (7). For more extensive aortic interventions, recent developments that affect access planning include advanced branch management, with multifenestrated, snorkel, and chimney grafts requiring secondary access sites for distalfacing and/or multiple target vessels. Secondary sites may include the upper extremities or carotid arteries. Preoperative planning includes evaluation of these individual access sites, and a backup plan to manage complications of each of these sites. In cases involving a lengthy procedure with a large contralateral femoral sheath, or multiple sheaths and catheters in place to manage multiple target vessels, one must intermittently direct intra-procedural attention to cumulative blood loss as well as occlusive time of the visceral vessels and limbs.

Once the procedure is complete and the patient is ready for closure, one must be prepared to identify potential access site complications such as dissections or perforations, as well as closure-device complications (stenosis, occlusion, or device failure). Routinely, equipment such as additional closure devices, percutaneous angioplasty balloons, covered stents, and surgical trays should be available for bailout procedures. Clear communication with the multidisciplinary team is paramount to managing rarer complications in an expeditious and effective manner.

\section{Conclusions}

Complex endovascular therapies for aortic pathology may require multiple arterial access sites. With a standardized approach to pre-operative, intra-operative, and post- operative vascular access management, optimal outcomes can be achieved.

\section{Acknowledgments}

Funding: None.

\section{Footnote}

Conflicts of Interest: The authors have no conflicts of interest to declare.

Open Access Statement: This is an Open Access article distributed in accordance with the Creative Commons Attribution-NonCommercial-NoDerivs 4.0 International License (CC BY-NC-ND 4.0), which permits the noncommercial replication and distribution of the article with the strict proviso that no changes or edits are made and the original work is properly cited (including links to both the formal publication through the relevant DOI and the license). See: https://creativecommons.org/licenses/by-nc-nd/4.0/.

\section{References}

1. Siracuse JJ, Farber A, Kalish JA, et al. Comparison of access type on perioperative outcomes after endovascular aortic aneurysm repair. J Vasc Surg 2018;68:91-9.

2. Biancari F, Mariscalco G, Mariani S, et al. Endovascular Treatment of Degenerative Aneurysms Involving Only the Descending Thoracic Aorta: Systematic Review and Metaanalysis. J Endovasc Ther 2016;23:387-92.

3. Baxter RD, Hansen SK, Gable CE, et al. Outcomes of Open Versus Percutaneous Access for Patients Enrolled in the GREAT Registry. Ann Vasc Surg 2021;70:370-7.

4. Torsello GF, Argyriou A, Stavroulakis K, et al. One-Year Results From the SURPASS Observational Registry of the CTAG Stent-Graft With the Active Control System. J Endovasc Ther 2020;27:421-7.

5. Torsello GF, Inchingolo $M$, Austermann $M$, et al. Durability of a low-profile stent graft for thoracic endovascular aneurysm repair. J Vasc Surg 2017;66:1638-43.

6. Lomazzi C, Mascoli C, de Beaufort HWL, et al. Gender Related Access Complications After TEVAR: Analysis from the Retrospective Multicentre Cohort GORE® GREAT Registry Study. Eur J Vasc Endovasc Surg 2020;60:203-9.

7. Meng M. Commentary on "Single nucleotide 
polymorphisms and risk of recurrence of renal-cell carcinoma: a cohort study." Schutz FA, Pomerantz MM, Gray KP, Atkins MB, Rosenberg JE, Hirsch MS, McDermott DF, Lampron ME, Lee GS, Signoretti S, Kantoff PW, Freedman ML, Choueiri TK, Dana-

Cite this article as: Sideman MJ, Hui DS. A standardized approach to access in patients requiring complex endovascular aortic therapy. Ann Cardiothorac Surg 2021;10(6):790-792. doi: 10.21037/acs-2021-taes-19
Farber Cancer Institute, Boston, MA 02115.: Lancet Oncol 2013;14(1):81-87. Epub 2012 Dec 7. doi: 10.1016/ S1470-2045(12)70517-X. Erratum in: Lancet Oncol 2013;14(3):e89. Urol Oncol 2014;32:512-3. 